\title{
CONHECIMENTO E HÁBITOS DE CONSUMO DE KEFIR NA COMUNIDADE ACADÊMICA DA UFMS
}

\section{Knowledge and consumption habits of kefir in the UFMS academic community}

\author{
Jedalia de Sousa Irmão ${ }^{1 *}$, Marcela de Rezende Costa ${ }^{l}$
}

\begin{abstract}
RESUMO
Alimentos lácteos fermentados utilizando grãos de kefir são consumidos não só pelo valor nutricional, mas também por seus aspectos probióticos. Assim, o interesse pelo kefir vem aumentando tanto pela população como pela comunidade científica. Porém, suas aplicações vão além da sua ingestão como leite fermentado, incluindo tecnologias explorando propriedades antimicrobianas e suas aplicações em conservação e embalagens para alimentos. O objetivo desse trabalho foi mensurar o nível de conhecimento sobre o kefir e o seu consumo por meio de uma pesquisa aplicada à comunidade acadêmica da UFMS. A coleta de dados foi feita por meio de questionário utilizando a plataforma Google Forms, cujo link foi enviado por email e presencialmente com o uso de um tablet. A análise dos dados revelou que $61,8 \%$ dos entrevistados conheciam o kefir e, destes, 22,2\% consumiam, porém, apenas $28,6 \%$ diariamente. Além disso, dos que consomem, a maioria ( $86 \%)$ utiliza o cultivo do produto em leite. A maioria apontou que o motivo do interesse no consumo está relacionado à saúde, sendo que o que eles mais relataram saber sobre o kefir é que faz bem para a saúde e suas formas de consumo e de produção. Participantes que disseram não conhecer o kefir, após breve explicação, responderam que produziriam em casa e consumiriam, caso ganhassem as mudas. Esse fato, juntamente com o restante dos dados obtidos, confirma o interesse por produtos considerados saudáveis e acessíveis (custo e facilidade), e apontam para um potencial de difusão dos conhecimentos e, assim, um maior consumo do kefir na comunidade.
\end{abstract}

Palavras-chave: probiótico; leite fermentado; saúde; consumidor.

1 Universidade Federal de Mato Grosso do Sul, Av. Costa e Silva, Cidade Universitária, 79070-900, Campo Grande, MS, Brasil. E-mail: jedaliasi19@gmail.com

* Autor para correspondência. 


\begin{abstract}
Fermented dairy products using kefir grains are consumed not only for nutritional value but also for their probiotic aspects. Therefore, the interest about kefir is increasing in the population as well in the academic community. However, its applications go beyond the intake of a fermented milk, including technologies exploiting antimicrobial properties and its applications in conservation and food packaging. The objective of this study was to measure the level of knowledge about kefir and its consumption through a research applied to the UFMS academic community. The data were obtained by a questionnaire using the Google Forms platform, through a link sent by email and in person using a tablet. The data analysis revealed that $61.8 \%$ of the participants have known kefir and, of these, $22.2 \%$ have consumed, however, only $28.6 \%$ daily. In addition, of those who consume, the majority $(86 \%)$ uses the cultivation of the product in milk. Most participants pointed out that the reason for the interest in consumption is related to health, and what they have most reported to know about kefir is that it is good for health and its methods of consumption and production. Participants who said they did not know kefir, after a brief explanation responded that they would produce at home and consume, if the seeds were gave to them. This fact, along with the rest of the data obtained, confirms the interest in products considered healthy and accessible (cost and easiness), and points to a potential of knowledge diffusion and, therefore, a greater consumption of kefir in the community.
\end{abstract}

Keywords: probiotic; fermented milk; health; consumer.

\section{INTRODUÇÃO}

Kefir é o nome dado ao leite fermentado produzido a partir de grãos próprios, contendo uma grande variedade de microrganismos. Também nomeado como quefir, tibicos, cogumelos tibetanos, plantas de iogurte, cogumelos do iogurte, kephir, kiaphur, kefer, knapon, kepi e kippi, de acordo com a região onde é cultivado (KEMP, 1984).

Pertencente ao grupo dos leites fermentados de acordo com a legislação brasileira, que estabelece a identidade e os requisitos mínimos de qualidade que deverão atender esse grupo de produtos lácteos destinados ao consumo humano no mercado interno brasileiro (BRASIL, 2007).

Os microrganismos mais comumente isolados de grãos de kefir compreendem os gêneros Lactobacillus (L. brevis, L. casei,
L. kefiri, L. acidophilus, L. plantarum, L. kefiranofaciens subsp. kefiranofaciens, L. kefiranofaciens subsp. kefirgranum, $L$. parakefir), Lactococcus (L. lactis subsp. lactis), Leuconostoc (L. mesenteroides), Acetobacter, Kluyveromyces (K. marxianus) e Saccharomyces (TAKIZAWA et al., 1998; WITTHUHN et al., 2005; CHEN et al., 2008).

A composição bioquímica, juntamente com a microbiológica, tem demonstrado que o kefir é um produto probiótico. Os probióticos são microrganismos utilizados para fermentar alimentos com a intenção principal de melhorar a microbiota intestinal com seu consumo, para isso são empregados frequentemente em leites fermentados, como o kefir (FARNWORTH, 2005). Resultados positivos têm sido observados com o uso de probióticos, como os encontrados no kefir, durante a fermentação na fabricação 
de produtos lácteos. Melhoram os valores nutricionais, pela liberação de aminoácidos livres e pela síntese de vitaminas, fornecendo propriedades terapêuticas (PARVEZ et al., 2006).

Além disso, determinados compostos antimicrobianos, como ácidos orgânicos, dióxido de carbono, etanol, polissacarídeos e bacteriocinas, são produzidos por espécies de Lactocbacillus, também encontradas no kefir, que possuem capacidade específica de interferir sobre microrganismos patógenos e bactérias capazes de deteriorar os alimentos não só durante a produção, mas também no período de armazenamento (MESSES; DE VUYST, 2002). Esses compostos são capazes de conferir aspectos sensoriais como textura agradável, sabor e aroma aos produtos.

No Brasil, a principal forma de consumo consiste na doação dos grãos de kefir entre conhecidos e através de grupos em redes sociais, onde acontecem doações e também troca de informações sobre o cultivo e receitas. Existe ainda o Projeto Kefir do Recôncavo da Universidade Federal do Recôncavo da Bahia (UFRB, 2017).

Os benefícios à saúde, tais como ser um alimento barato, de fácil cultivo e a variedade de aplicações, levaram ao objetivo de investigar o conhecimento e o consumo de kefir em um grupo populacional, cujo interesse pelo tema possa ser despertado.

\section{MATERIAL E MÉTODOS}

Essa pesquisa foi conduzida na comunidade universitária da UFMS, campus de Campo Grande/MS. A mesma foi realizada por meio de entrevistas contendo questões que visavam avaliar o grau de conhecimento e qual o hábito de consumo de kefir. Foi aplicado um questionário (Figura 1), visando ampliar as informações e as discussões sobre o tema, envolvendo opinião, preferências e percepções dos participantes, já que a apli- cação de um questionário possibilita obtenção de dados de forma rápida, eficaz e econômica (GIL, 2008).

O questionário foi construído na plataforma Google Forms e aplicado eletronicamente de duas maneiras: (1) abordando pessoalmente os participantes no campus, que responderam o questionário através do aplicativo instalado em um tablet conectado à internet, e (2) por meio de um link que deu acesso ao questionário eletrônico, enviado por e-mail para acadêmicos, docentes e técnicos.

Esse estudo seguiu os preceitos éticos da resolução 466/2012 do Ministério da Saúde (BRASIL, 2012), que contém diretrizes e normas para a pesquisa com seres humanos, e foi submetido ao Comitê de Ética em Pesquisa da UFMS. Ele foi aplicado somente após sua aprovação pelo mesmo; e a participação de qualquer membro da UFMS na pesquisa foi voluntária. A pesquisa contou com a participação de 102 pessoas vinculadas à UFMS, maiores de 18 anos. Todas concordaram com a participação por meio do aceite ao "Termo de Consentimento Livre e Esclarecido" do estudo. Posterior à aplicação do questionário, foram realizadas a compilação e a análise dos dados, incluindo análise estatística descritiva das questões.

\section{RESULTADOS E DISCUSSÃO}

Dos convidados a participar da pesquisa, 102 responderam ao questionário. A faixa etária variou entre 18 e 68 anos, sendo que a maioria (28\%) estava na faixa de 20 a 25 anos. Dos participantes, 65,7\% eram mulheres e os acadêmicos de graduação representaram $54,9 \%$. O fato de a maioria que respondeu ter se declarado mulher, pode demonstrar que esse grupo seja o mais interessado em assuntos de consumo de alimentos ou de alimentos considerados saudáveis. 


\section{Pesquisa: "KEFIR: CONHECIMENTO E CONSUMO"}

1. Qual a sua idade? anos

2. Gênero: （ ) Feminino

3. Qual o seu vínculo com a UFMS?

( ) Docente

( ) Aluno de graduação

4. Na UFMS, qual a sua unidade?
( ) Masculino ( ) Outro

( ) Técnico administrativo ou de laboratório

( ) Aluno de pós-graduação

5. Quais alimentos considerados saudáveis você consome no seu dia a dia?
( ) Não consumo esse tipo de alimento
( ) Iogurtes e/ou similares
( ) Frutas
( ) Verduras e/ou legumes
( ) Alimentos integrais
( ) Outros:

6. Se você consome iogurtes e produtos semelhantes, com qual frequência costuma consumir?
( ) Não consumo esse tipo de alimento
( ) De vez em quando, sem uma rotina definida
( ) Diariamente
( ) Três vezes na semana
( ) Duas vezes na semana ou menos

7. Você conhece ou já ouviu falar em um produto chamado "KEFIR"? De que maneira?

( ) Não conheço

( ) Consumo ou já consumi

( ) Amigos ou pessoas da minha família consomem ou já consumiram

( ) Apenas conheço pela internet, TV ou outro meio de comunicação

( ) Outro:

8. O que você sabe sobre o KEFIR?
( ) Não conheço
( ) Só conheço, não sei nada específico
( ) Sua origem/história
( ) A forma de produzir o kefir
( ) Que faz bem para a saúde
( ) A(s) maneira(s) de consumir o kefir

( ) Outro:

9. Se você souber, cite alguns benefícios do kefir para a saúde.

10. Com qual frequência você costuma consumir o kefir?

( ) Não consumo esse tipo de alimento

( ) Diariamente

( ) De vez em quando, sem uma rotina definida

( ) Três vezes na semana

( ) Duas vezes na semana ou menos

11. Qual o motivo principal de você consumir o kefir?

( ) Não consumo

( ) Consumo porque eu gosto

( ) Consumo porque faz bem à saúde

12. Qual tipo de kefir você costuma consumir?

( ) Cultivado em água e açúcar mascavo

( ) Cultivado em leite

13. De que forma você costuma consumir o kefir? *
( ) Puro, natural ou adoçado
( ) Batido com frutas
( ) Outra:

14. O kefir é um alimento probiótico normalmente adicionado ao leite, dando origem a uma bebida fermentada, semelhante a um iogurte líquido. Mas pode também ser cultivado em água com adição de açúcar mascavo. Sua produção é feita através da adição de "sementes" ou "grãos" de kefir ao leite ou à água. Essas sementes ou grãos são formados por diversos microrganismos, sendo que vários podem proporcionar benefícios à sua saúde. Após a fermentação, o produto é filtrado e os grãos separados podem ser utilizados novamente para fermentação. O leite ou a água fermentada, em geral, são consumidos puros ou com adição de açúcar, de frutas ou de outros ingredientes. O kefir, em geral, é produzido de maneira artesanal e nas décadas de 80 e 90 foi amplamente consumido no Brasil e era disseminado na forma de doação de "mudas", prática de multiplicação de usuários que é utilizada até hoje.

Depois dessas informações sobre o kefir, você consumiria, caso ganhasse as sementes para produzi-lo?
( ) Já consumo
( ) Produziria em casa e consumiria
( ) Não consumiria
( ) Só consumiria se fosse comprado em algum tipo de mercado

15. Gostaria de fazer mais algum comentário sobre o kefir?

Figura1 - Questionário aplicado para a realização da pesquisa 
O menor grupo foi o de técnicos adminisrativos ou de laboratório com $12,7 \%$ das respostas.

Vinte e um setores da UFMS responderam ao questionário, dentre os quarenta e um setores para os quais foi encaminhado o questionário, sendo que os que mais contribuíram foram a Faculdade de Ciências Farmacêuticas, Alimentos e Nutrição (FACFAN) com $41,2 \%$ dos participantes e a Faculdade de Medicina Veterinária e Zootecnia (FAMEZ) com $11,8 \%$.

$\mathrm{O}$ percentual de participantes que de- clararam consumir alimentos considerados saudáveis foi de $98 \%$, mostrando que quase a totalidade dos participantes de alguma maneira busca se alimentar de maneira saudável diariamente. Na Figura 2, pode-se verificar que esses afirmaram consumir principalmente legumes e verduras $(90 \%)$ e frutas $(87 \%)$. A facilidade de transporte e acondicionamento pode facilitar o consumo desses alimentos na universidade, já que muitos deles não dependem de refrigeração para sua conservação. Além disso, o restaurante universitário, onde boa parte dos participantes

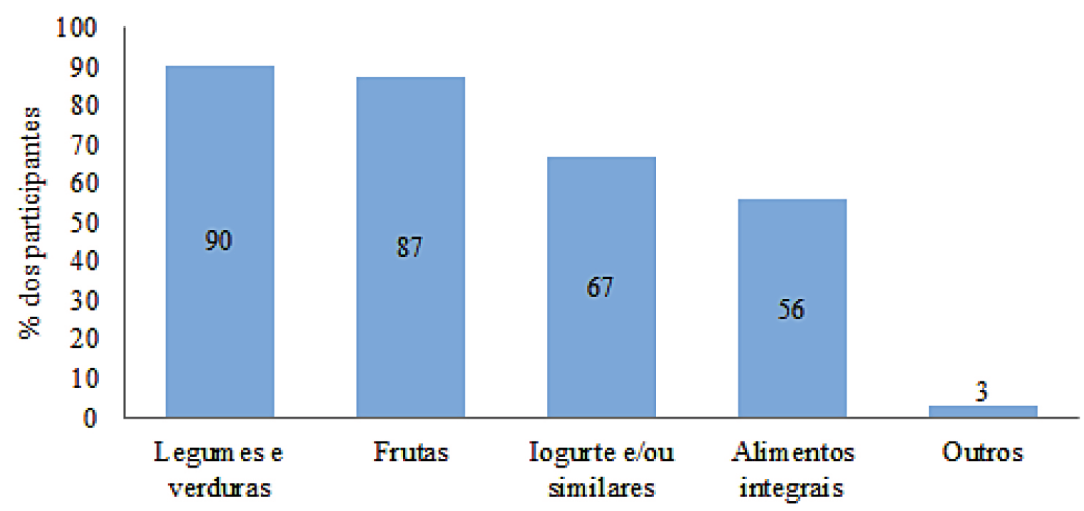

Figura 2 - Frequência de respostas para a pergunta: Quais alimentos considerados saudáveis você consome no seu dia a dia?

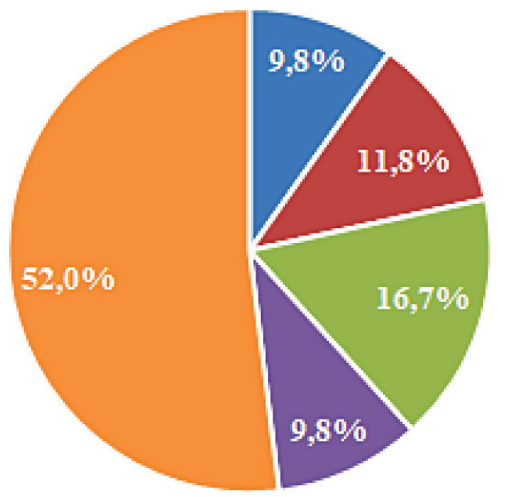

- Não costumo consum ir

- Diariam ente

- Três vezes na semana

- Duas vezes tha semana ou menos

- De vez em quando, sem uma rotina definida

Figura 3 - Frequência de respostas para a pergunta: Se você costuma consumir iogurte e/ou produtos semelhantes, com qual frequência costuma consumir? 
almoça e/ou janta, serve diariamente saladas variadas e a sobremesa é, muitas vezes, uma fruta.

O consumo de iogurte e/ou similares foi declarado por $90,2 \%$ dos entrevistados, porém verificou-se que não há uma rotina definida para esse consumo (52\%) (Figura 3). Essa categoria de alimento tem o seu consumo dificultado ao longo do dia de pessoas que saem de casa pela manhã e só retornam à noite, como é o caso da maioria na universidade, já que esses produtos lácteos exigem que sejam mantidos sob refrigeração, talvez por isso seja difícil manter uma rotina de consumo.

Dentre os $61,8 \%$ dos participantes que declararam conhecer ou já ter ouvido falar do kefir, 38\% consomem ou já consumiram e $27 \%$ têm amigos ou familiares que consomem ou já consumiram (Figura 4). Esse fato pode estar relacionado às experiências domésticas comuns nas décadas de 70, 80 e até meados da década de 90 , quando o kefir era conhecido como iogurte caseiro e consumido apenas adoçado com açúcar ou mel, sendo uma alternativa mais barata aos iogurtes comerciais vendidos a preços nem sempre acessíveis à população de menor renda e que, muitas vezes, não possuía geladeira para conservação dos alimentos. Com o passar

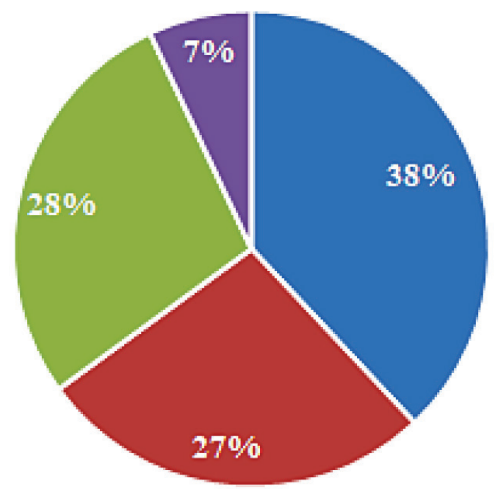

do tempo e mudanças nas rotinas das famílias, o kefir deixou de ser consumido, tendo retornado recentemente como alternativa alimentar saudável e barata. Atualmente, os grãos bem como formas diversificadas de consumo, incluindo alternativas gourmets, são compartilhados nas redes sociais. Inclusive, a pesquisa revelou que $28 \%$ dos entrevistados afirmaram ter conhecido o kefir por meio de algum meio de comunicação, como TV ou internet.

Os que declararam conhecer o kefir afirmaram, principalmente, saber que o kefir faz bem à saúde (67\%), que sabem a forma de consumir $(52 \%)$ e de produzir $(49 \%)$ (Figura 5). Essas informações podem auxiliar na tomada de decisões para ações tanto para estimular o consumo do kefir como para contribuir com o seu cultivo através da distribuição de grãos.

Dentre os entrevistados que conhecem o kefir, $22,2 \%$ declararam consumir kefir, sendo diariamente $(28,6 \%)$ ou três vezes por semana $(28,6 \%)$. Porém, ainda $28,6 \%$ não têm uma frequência definida de consumo (Figura 6). A alegação de que faz bem à saúde foi o principal motivo para o consumo (86\%), mas $36 \%$ afirmaram que consomem porque gostam do produto. Muitas vezes, o kefir não faz parte dos alimentos consumidos regularmente,

- Consumo ou jả consumi

- Amigos ou familia consom em ou já consumiram

- Apenas conheço por internet, TV ou outros m eios de comunicação

- Outros

Figura 4 - Frequência de respostas para a pergunta: De que maneira você conhece o kefir? 
provavelmente porque exige uma rotina de preparo e também pela necessidade de manter o produto kefirado sob refrigeração, o que dificulta seu transporte e acondicionamento durante o período em que esses consumidores permanecem fora de casa.

Quando indagadas se saberiam citar algum dos benefícios do kefir para a saúde, as respostas, no total de vinte e oito, foram diversas. Os entrevistados reportaram, principalmente, auxílio à microbiota intestinal, melhoria ou normalização da motilidade e do fluxo gastrointestinal, benefícios para integridade da mucosa intestinal, auxílio no controle de diabetes, que faz bem para a pele, que é probiótico, e melhoria do sistema imunológico. Esses e outros benefícios já foram relatados em diversos estudos científicos (SEPPO et al., 2003; CAO, FERNANDEZ, 2005; SAAD, 2006).

Neste estudo, verificou-se que, dos entrevistados que consomem o kefir, apenas

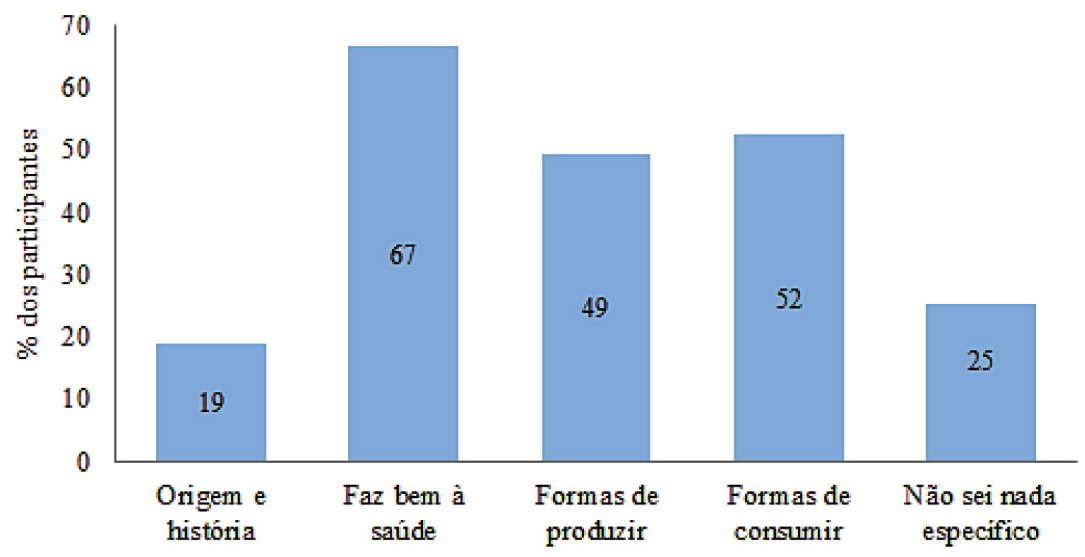

Figura 5 - Frequência de respostas para a pergunta: O que você sabe sobre o kefir?

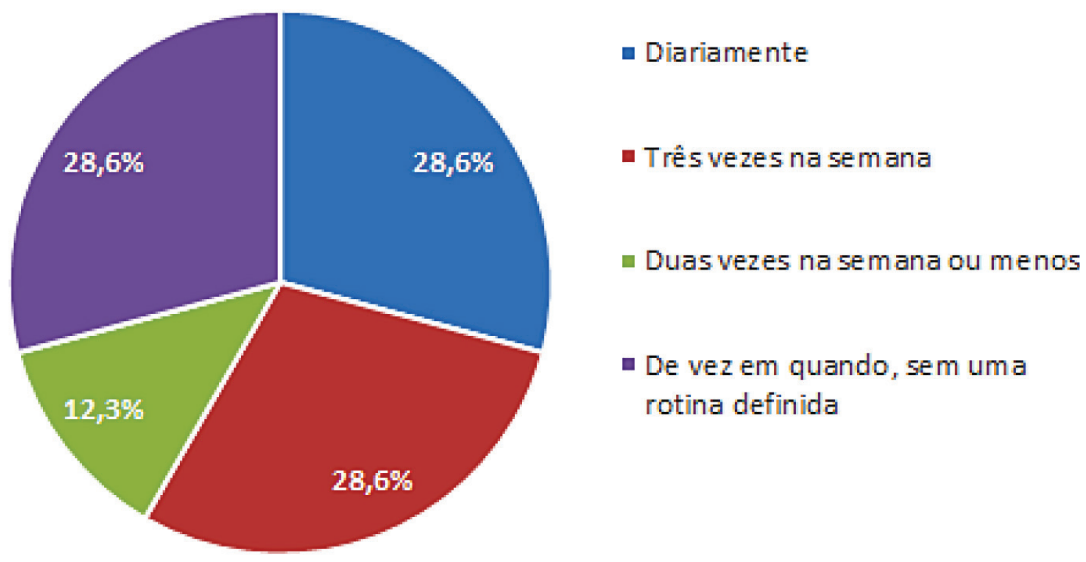

Figura 6 - Frequência de respostas para a pergunta: Com qual frequência você costuma consumir kefir? 
$14 \%$ consomem o cultivado em água. O kefir é mais cultivado em leite ( $86 \%$ ) e consumido, principalmente, batido com frutas (57\%) (Figura 7). É possível que essa preferência em cultivar o kefir em leite esteja de alguma maneira relacionada com a prática do iogurte caseiro das décadas de 70,80 e 90. O teor de acidez do kefir, até 1\% (BRASIL, 2007), pode ser o responsável pelo fato dos consumidores preferirem que seja acrescido de frutas ou adoçado com açúcar, açúcar mascavo ou mel, amenizando a sensação ácida e facilitando seu consumo.

Ao final do questionário foram dadas informações científicas sobre o kefir aos entrevistados, como: o que é, formas de cultivo e de consumo, e seus benefícios. Depois foi perguntado se a pessoa produziria em casa e consumiria o produto, caso ganhasse a muda. Dos entrevistados, 49\% responderam que sim (Figura 8), provavelmente devido aos benefícios apresentados. Porém, 33,3\%, só

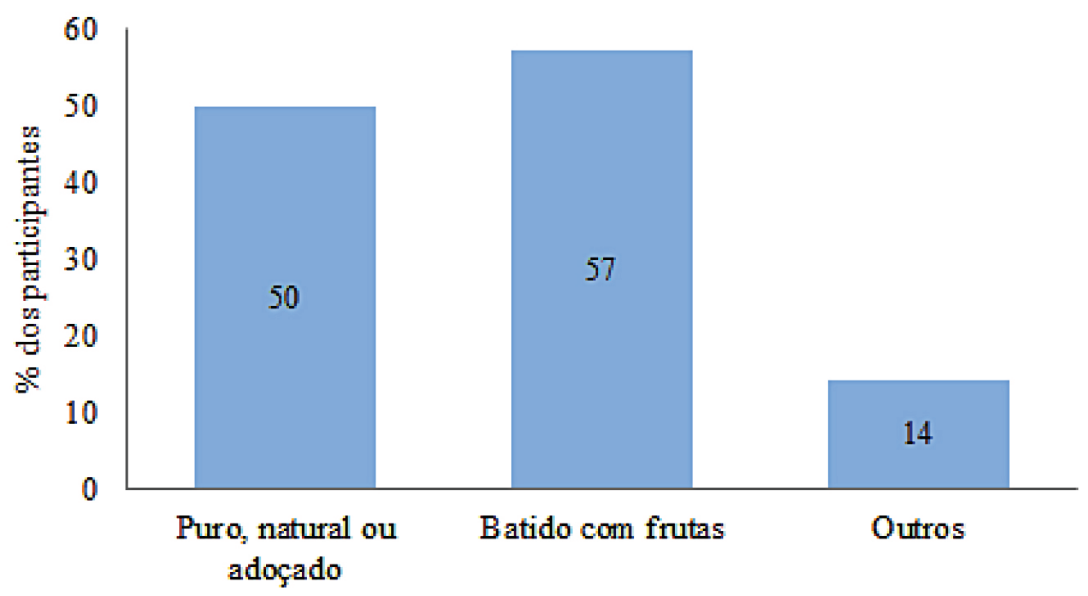

Figura 7 - Frequência de respostas para a pergunta: De que forma você consume o kefir?

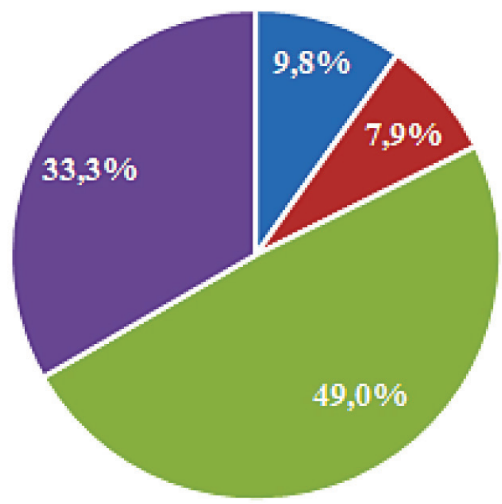

- Já consumo

- Não consumiria

- Produziria em casa e consum iria

- Só consumiria se fosse comprado em algum tipo de $m$ ercado

Figura 8 - Frequência de respostas para a pergunta: Você consumiria o kefir, caso ganhasse as sementes para produzi-lo? 
consumiriam se pudessem comprar o produto pronto no mercado formal. Nesse caso, provavelmente, essa escolha esteja relacionada à busca de uma segurança no consumo e também porque sua produção caseira exija uma rotina de preparo. Apenas 7,9\% não consumiriam. Alguns entrevistados relataram o não consumo relacionado a não aceitação do sabor, da alta acidez, e de sensibilidade ao leite.

Dados relativamente recentes (GALAN, 2016), mostram que o consumo de produtos lácteos vem caindo ao longo dos anos desde 2012, provavelmente devido aos problemas econômicos no Brasil, desemprego e queda da renda de uma parcela da população. Os leites fermentados, em particular, tiveram uma queda acentuada na demanda, $17 \%$ só em 2015. A produção caseira do kefir seria uma alternativa viável para algumas famílias retomarem o consumo de produtos lácteos, especialmente de fermentados, por ser um alimento nutritivo, probiótico, e de baixo custo de produção. Além disso, como mostrado nesse estudo, o conhecimento sobre o kefir já existe em uma boa parcela da comunidade, porém seu consumo ainda é restrito.

$\mathrm{O}$ mercado tem mostrado alguns aspectos específicos, que são importantes para o aumento do interesse por determinados produtos, como os lácteos: retomada do interesse por cozinhar em casa por conforto, exclusividade e indulgência. Dentre as maiores forças que vêm definindo a indústria de alimentos e bebidas desde 2012 estão: naturalidade, energia, saúde digestiva, "sinta o benefício", laticínios e grãos. O impulso na popularidade dos leites fermentados se deve à: relação desses produtos com a melhoria da saúde, a simplicidade da tecnologia de produção, baixo custo e longa vida-deprateleira (GARLINA, 2013). O kefir e suas características vêm de encontro a todos esses aspectos, mostrando-se um produto ainda a ser bastante explorado. Esse trabalho mostra alguns dados iniciais que podem direcionar pesquisas ainda mais abrangentes sobre o tema e ajudar a divulgar e desenvolver o assunto.

\section{CONCLUSÕES}

Os resultados da pesquisa mostram que o conhecimento sobre o kefir, seu cultivo e alternativas de consumo estão relativamente presentes na comunidade acadêmica da UFMS em Campo Grande. A maioria ainda não consome o produto, mas demonstra interesse em consumir. Assim, esse estudo demonstra que são viáveis ações de incentivo ao seu consumo por ser um alimento probiótico, barato e com características sensoriais aceitas pela maioria dos consumidores.

\section{REFERÊNCIAS}

BRASIL. Ministério da Agricultura, Pecuária e Abastecimento (MAPA). Instrução Normativa $n^{\circ} 46$, de 23 de outubro de 2007. Adota o Regulamento Técnico de Identidade e Qualidade de Leites Fermentados, anexo à presente Instrução Normativa. Diário Oficial da República Federativa do Brasil, Brasília, 24 out 2007. Seção 1, p. 4.

BRASIL. Ministério da Saúde (MS) - Conselho Nacional de Saúde. Resolução n 466 , de 12 de dezembro de 2012. Aprova as diretrizes e normas regulamentadoras de pesquisa envolvendo seres humanos. Diário Oficial da República Federativa do Brasil, Brasília, 13 jun 2013. Seção 1, p. 59.

CAO, Y. C.; FERNÁNDEZ, A. F. Probióticos y reflexión necesaria. Revista Cubana de Medicina General Integral, v. 21, p. 3-4, 2005.

CHEN, H.; WANG, S.; CHEN, M. Micro- 
biological study of lactic acid bacteria in kefir grains by culture-dependent and cultureindependent methods. Food Microbiology, v. 25, n. 3, p. 492-501, 2008.

FARNWORTH, E. R. Kefir: a complex probiotic. Food Science and Technology, Bulletin: Functional Foods, v. 2, n. 1, p. 1-17, 2005.

GIL, A. C. Métodos e técnicas de pesquisa social. $6^{\mathrm{a}}$ ed. São Paulo: Atlas, cap. 12, p. 121-134, 2008.

GALAN, V.; CARVALHO, M. P.; VENTURINI, C. Cenário atual e perspectivas do mercado lácteo em 2016. Disponível em: <http://www.aliancalactea.org. br/wp-content/uploads/2016/05/160524ALS-24.05.2016.pdf $>$. Acesso em: 30 nov 2017.

GARLINA, D. Inovações na área de leites fermentados. Campinas: ITAL, 2013. Disponível em: <http://www.ital.sp.gov.br/ tecnolat/anais/t1230513/Arquivos/Darlila\% 20Gallina_ITAL.pdf>. Acesso em: 30 nov. 2017.

KEMP, N. Kefir, the champagne of cultured dairy products. Cultured Dairy Products Journal, v. 19, n. 3, p. 29-30, 1984.

MESSES, W.; DE VUYST, L. Inhibitory substances produced by lactobacilli isolated from sourdoughs - a review. International
Journal of Food Microbiology, v. 72, p. 31-43, 2002.

PARVEZ, S. et al. Probiotics and their fermented food products are beneficial for health. Journal of Applied Microbiology, v. 100, n. 6, p. 1171-1185, 2006.

SAAD, S. M. I. Probióticos e prebióticos: o estado da arte. Revista Brasileira de Ciências Farmacêuticas, v. 42, n. 1, p. 1-16, 2006.

SEPPO, L.; JAUHIAINEM, T.; POUSSA, T.; KORPELA, R. A fermented milk high in bioactive peptides has a blood pressurelowering effect in hypertensive subjects. American Journal of Clinical Nutrition, v. 77, p. 326-330, 2003.

TAKIZAWA, S. et al. The composition of the Lactobacillus flora in kefir grains. Systematic and Applied Microbiology, v. 21, n. 1, p. 121-127, 1998.

UNIVERSIDADE FEDERAL DO RECÔNCAVO DA BAHIA - UFRB. Kefir do Recôncavo. Disponível em: $<$ https://www2. ufrb.edu.br/kefirdoreconcavo/>. Acesso em: 21 jul 2017.

WITTHUHN, R. C.; SCHOEMAN, T.; BRITZ, T. J. Characterization of the microbial population at different stages of Kefir production and Kefir grain mass cultivation. International Dairy Journal, v. 15, n. 4, p. 383-389, 2005. 